\title{
Diálogo examinativo: proposta de um modelo dialético para a promoção do pensamento crítico em sala de aula
}

\author{
Examination dialogue: proposal of a dialectical model for the promotion of \\ critical thinking in classroom.
}

\author{
Daniel Filipe Rodrigues Cabral \\ Graduado na Universidade Federal do Espírito Santo, Vitória, ES, Brasil. \\ dfrcabral@hotmail.com - https://orcid.org/0000-0001-6869-9741
}

Recebido em 21 de dezembro de 2020

Aprovado em 01 de junho de 2021

Publicado em 24 de junho de 2021

RESUMO: O pensamento crítico pode ser definido como o pensamento razoável e reflexivo acerca do que fazer ou em que acreditar. Sua inserção e fomento nas escolas e universidades consiste em um ideal defendido por filósofos da educação desde, pelo menos, o início do séc. XX. O pensador crítico ideal, arquétipo desenvolvido para representar o indivíduo que idealmente pensa criticamente quando é apropriado e o faz bem, pode ser caracterizado por suas habilidades e disposições. Uma dissonância surge ao contrastar as disposições do que seria o pensador crítico ideal e sua viabilidade como objetivo educacional com evidências provindas de estudos empíricos as quais sugerem tendências a vieses cognitivos e a outras falhas de raciocínio características do ser humano ao avaliar e construir juízos e operar logicamente. Embora, não obstante a essas evidências, haja boas razões para considerar o desenvolvimento do pensamento crítico uma meta viável de ser alcançada e válida de ser perseguida educacionalmente, a literatura disponível carece de modelos pragmáticos que contribuam para o exercício de tais disposições em um ambiente de sala de aula. Este artigo defende a interpretação de uma estrutura dialética, o diálogo examinativo, como uma ferramenta pedagógica válida e eficaz no exercício e no desenvolvimento de algumas disposições daquele que pensa criticamente. Argumentarei que esse modelo propicia a formação de hábitos convenientes ao ambiente de diálogo e articulação de ideias característico de contextos educacionais que buscam o pensamento crítico como um de seus paradigmas.

Palavras-chave: Pensamento crítico; Diálogo examinativo; Nova dialética; Filosofia da educação.

ABSTRACT: Critical thinking can be defined as a reasonable and reflective kind of thinking about what to do or believe. Its insertion and promotion in schools and universities consists of an ideal supported by philosophers of education since, at least, the beginning of the 20th century. The ideal critical thinker, an archetype designed to represent the individual who ideally thinks critically when it is appropriate and does it well, can be characterized by his abilities and dispositions. A dissonance arises when we contrast the dispositions of what would be the ideal critical thinker and its viability as an educational goal with evidence from empirical studies that suggest tendencies to cognitive biases and other reasoning flaws characteristic of humans when evaluating and arriving at judgments and operating logically. Although, despite such evidence, there are good reasons to consider the development of critical thinking as a achievable and valid goal to to be pursued educationally, the available literature lacks pragmatic models that contribute to the exercise of such dispositions in an environment of classroom. This papper defends the interpretation of a dialectical structure, the examination dialogue, as a valid and effective pedagogical tool in the exercise and 
development of some dispositions of someone who thinks critically. I will argue that this model supports the acquisition of habits suitable to the environment that favors dialogue and articulation of ideas characteristic of educational contexts that seek critical thinking as one of its paradigms.

Keywords: Critical thinking; Examination dialogue; New dialectic; Philosophy of education

\section{Introdução}

Na literatura disponível sobre o assunto, encontramos diferentes formulações do que seja o pensamento crítico. Nesta pesquisa, adotarei a definição que o caracteriza como o pensamento razoável e reflexivo quanto ao que fazer ou em que acreditar (ENNIS, 1991). Também será adotada a visão de que o pensamento crítico é orientado por critérios (GUZZO, Guilherme.; GUZZO, Valdemir, 2015) e que a principal diferença entre aquele que pensa criticamente e aquele que não o faz não está expressa na asserção equivocada de que o primeiro pensa e o segundo não, mas na noção de que o primeiro está ciente dos passos lógicos que norteiam seu raciocínio enquanto o segundo não possui ciência desses passos ou a possui em menor grau (HOAGLUND, 1993).

O processo de pensar criticamente engloba a identificação e a análise de problemas, o esclarecimento de significados, a coleta e a avaliação de evidências e a inferência de conclusões. Esse processo difere da pura apreciação lógica argumentativa por não se limitar à análise de argumentos isolados, por possuir um componente criativo bem como disposições e hábitos mentais característicos e por envolver a avaliação criteriosa das evidências disponíveis (HITCHCOCK, 2017). Sobre essas diferenças,

Ao pensar criticamente, não queremos apenas descobrir se um único argumento é forte ou fraco. Também queremos saber mais sobre seu contexto e vê-lo em uma estrutura mais ampla de escolhas, maneiras ou opções alternativas. Queremos traçar o melhor caminho para a compreensão de um problema e tomar a melhor decisão sobre ele. Também analisamos até que ponto todos os nossos julgamentos e decisões são apoiados por evidências ao passo que examinamos a qualidade das mesmas. (Ibid., p.484) 1 .

A promoção e a inserção do pensamento crítico em sala de aula são defendidas por filósofos da educação desde, pelo menos, o início do séc. $X X$, movimento que atingiu 
seu ápice - no século passado - entre as décadas de 1970 e $1980^{2}$, especialmente na América Anglo-Saxônica. Ainda mais, encontramos, na literatura atual disponível, argumentos em favor da visão de que é necessário que escolas e universidades atentem para a formação intelectual, associada ao fortalecimento do pensamento crítico, de seus estudantes (GUZZO; LIMA, 2018) e que a promoção e o desenvolvimento das competências e disposições características de um pensador crítico devem compor um dos objetivos de qualquer sistema de ensino (HITCHCOCK., 2017).

Aqui, podemos indagar quais papéis o pensamento crítico, tal como descrito no presente trabalho, pode ter em nossa vida e por quais razões o mesmo deveria ser ensinado e fomentado nos estudantes de escolas e universidades. Sobre o tema,

A capacidade de pensar criticamente (...) é uma habilidade importante na vida. De tempos em tempos, todos encontramos perplexidades quanto ao que acreditar ou o que fazer, seja na vida cotidiana, seja em ocupações especializadas. O pensamento crítico hábil é, por definição, mais suscetível de levar a uma resolução satisfatória de tais perplexidades do que reagir automaticamente ou refletir inadequadamente. A disposição de responder às perplexidades com um pensamento crítico hábil é, portanto, útil para qualquer pessoa na administração de sua vida (HITCHCOCK, 2017, p. 488) ${ }^{3}$.

Além disso, é possível enxergar o pensamento crítico como ferramenta de defesa intelectual contra a desinformação e a manipulação (GUZZO; GUZZO, 2015). Vivemos em um contexto de grande fluxo de informações em que somos, com frequência, deliberadamente expostos a asserções falsas como se essas fossem verdadeiras. Isso configura uma tentativa de alguns de nossos interlocutores de manipular nossas opiniões e crenças sobre os mais diversos assuntos, abrangendo questões políticas, econômicas, sociais, etc. A análise cuidadosa, o pensamento claro e a deliberação racional, característicos do pensamento crítico, permitem que o indivíduo separe informações confiáveis e plausíveis de informações que provavelmente são falsas. Um indivíduo, ao pensar criticamente, tende a não aceitar afirmações que lhes pareçam questionáveis sem que haja razões que as suportem, o que acreditamos constituir uma virtude intelectual essencial ao exercício da vida democrática. 
Portanto, pensamos que o desenvolvimento do pensamento crítico nos estudantes, bem como em qualquer cidadão no geral, pode fornecê-los mecanismos de defesa não só contra a manipulação intelectual e a desinformação como também contra a doutrinação, o que reitera a necessidade de que "escolas e universidades empreguem esforços para destacar o pensamento crítico em suas atividades educacionais" (GUZZO; GUZZO, 2015, p.71).

\section{Habilidades e disposições de um pensador crítico e sua viabilidade como meta educacional}

Um ponto importante de ressaltar, como sinalizam Guilherme e Valdemir Guzzo (Ibid., p.67), é que, meramente, possuir as habilidades cognitivas apropriadas não necessariamente faz de uma pessoa um pensador crítico. Também é preciso que haja um conjunto de disposições de comportamento que tornem o emprego de tais competências um habito constante na vida do indivíduo, ainda que o processo considere ideias contrárias aos seus próprios interesses e às suas crenças mais arraigadas. Sobre isso, Hitchcock (2017, p.482) escreve que "[...] é mais útil olhar para além das definições e se atentar às descrições das habilidades características e das atitudes e tendências comportamentais de um 'pensador crítico"'4.

A relação do que seriam as habilidades e disposições distintivas de um pensador crítico é vasta. Dentre as habilidades de um pensador crítico ideal ${ }^{5}$, são listadas a interpretação, análise e avaliação de informações e evidências (FACIONE,1990), a análise de argumentos e a capacidade de extrair conclusões lógicas de um conjunto de premissas (HITCHCOCK, 2017), a capacidade de formular perguntas e respostas que clarifiquem ou desafiem algum ponto de vista e o julgamento da credibilidade de fontes de informação (ENNIS, 1991). Dentre as disposições ou hábitos mentais ${ }^{6}$, encontram-se a flexibilidade na consideração de alternativas e opiniões; honestidade em enfrentar os próprios vieses e preconceitos; mente aberta quanto a diferentes visões de mundo e vontade de reconsiderar e revisar pontos de vista quando uma reflexão honesta sugere que a mudança é justificada (FACIONE,1990). Além disso o 
pensador crítico ideal possuiria mente aberta e justa, seria atento às opiniões de outras pessoas e suas razões subjacentes e proporcionaria suas crenças às evidências disponíveis (HITCHCOCK, 2017).

Aqui, nosso foco serão as disposições características de um pensador crítico ideal as quais subsumimos na seguinte relação:

Conjunto de disposições de um pensador crítico

1. Mente aberta, flexibilidade, atenção e séria consideração de diferentes visões de mundo e opiniões, bem como às razões subjacentes às mesmas.

2. Sensibilidade aos próprios vieses, preconceitos e tendências e honestidade ao enfrentá-los.

3. Reconsideração e revisão dos próprios pontos de vista quando uma reflexão honesta sugere que a mudança é justificada.

4. Adequar as próprias crenças às evidências disponíveis.

A razão para esse recorte é a observação de que as disposições de um pensador crítico congregadas acima contrastam com uma série de preconceitos, tendências e vieses característicos dos seres humanos evidenciados pela literatura. Como aponta McCain (2016), ao que sugerem as evidências empíricas de que dispomos sobre o assunto, estamos sujeitos a diversos processos enviesados e irracionais quando construímos nossas crenças e falhamos sistematicamente ao raciocinar sobre questões oriundas de diversos domínios.

Guilherme Guzzo e Valderez Lima (2018) apontam diferentes estudos que tocam no tema. Por exemplo, evidências provindas de áreas como a psicologia cognitiva, evolutiva e social sugerem que (1) o raciocínio sobre questões morais é tipicamente uma construção post hoc, ou seja, um processo desencadeado após um julgamento já ter sido alcançado e que (2) tal julgamento é geralmente resultado de intuições (avaliações rápidas e automáticas) e fortemente influenciado por fatores socioculturais (HAIDT, 2001). Em outras palavras, parece ser o caso que, diante de uma situação moral controversa, indivíduos automaticamente avaliam determinada situação à luz de juízos préestabelecidos e, quando uma justificativa verbal lhes é demandada, desempenham o 
papel de defender racionalmente a posição assumida ao invés de buscar a posição mais razoável e condizente com as evidências e fatos. Ademais, indivíduos que possuem opiniões fortes acerca de questões sociais complexas têm a propensão de examinar evidências empíricas de modo enviesado. Expor indivíduos de opiniões fortes divergentes sobre alguma questão social complexa controversa a um corpo balanceado de evidências empíricas não só pode não contribuir para o estreitamento do desacordo como também pode contribuir, e tende a contribuir, para a intensificação da polarização já existente (LORD; ROSS; LEPPER; 1979). Em suma, o que esses e outros estudos relacionados nos sugerem é que há diversos mecanismos que "podem contribuir para desencorajar o espírito crítico e limitar ou dificultar o exercício das habilidades do pensamento crítico" (GUZZO; LIMA, 2018, p.338).

Não obstante, há boas razões para acreditar que é possível e necessário defender a ideia de pensamento crítico e investir em seu desenvolvimento em escolas e universidades (Ibid.). Mesmo que processos não racionais desempenhem importante papel em nossos mecanismos cognitivos, tal fato apenas dificulta, mas não impede que indivíduos possam tornar-se hábeis em avaliar ideias e razões (Ibid., p.335). Além disso, é perfeitamente possível que sujeitos que pensam racionalmente sobre questões de naturezas diversas e que foram expostos a razões, as analisaram e por essas razões foram movidos passem a enxergar, ao menos em algum grau, tais questões de outra maneira, isso é, sob uma perspectiva mais crítica (GUZZO; LIMA, 2018).

Por fim, de modo semelhante, McCain (2016) afirma que,

Embora haja evidências da irracionalidade humana, nós possuímos meios de manter esse tipo de irracionalidade contida para que não "infecte" todas as nossas crenças. Portanto, enquanto estamos propensos a cometer erros sistemáticos em certos casos, estamos cientes de nossas tendências e podemos tomar medidas para combater nossas deficiências naturais. (Ibid.) ${ }^{7}$.

\section{Pensamento crítico e dialética}

Embora os argumentos que defendem o pensamento crítico como meta viável constituam um quadro promissor, a literatura disponível demanda investigação quanto a 
estratégias pragmáticas que possam ser adotadas para estimular o desenvolvimento das habilidades e disposições de um pensador crítico. Hitchcock (2017) defende que a chave para o desenvolvimento dessas habilidades e disposições é estar ciente da maneira como pensamos e trabalhar para aprimorar nosso pensamento tendo algum modelo como referência.

Seguindo essa premissa, indagamos quais tipos de modelos podem ser adotados para atingir esse objetivo. Guzzo e Lima (GUZZO; LIMA, 2018) nos indicam um dos caminhos possíveis,

\begin{abstract}
O pensamento crítico implica no reconhecimento da falibilidade de nossas ideias e, por isso, requer permanente atenção a como pensamos e tomamos decisões. Pensar criticamente também significa tentar, na medida das possibilidades, seguir a autoridade dos bons argumentos ao invés de ser fiel [...] às nossas preconcepções. A incorporação destas características demanda tempo e esforço intelectual. Nas escolas e universidades, estudantes e professores devem criar ambientes favoráveis ao diálogo, fortalecendo o hábito de oferecer razões para os seus próprios pontos de vista, e demandando razões para as ideias a que são apresentados, ao mesmo tempo em que consideram a possibilidade de que possam estar errados sobre alguma questão, e, por isso, estão dispostos a ajustar as suas crenças e maneiras de pensar se houver bons motivos para isso. (GUZZO; LIMA, 2018, p. 342).
\end{abstract}

Tendo essa linha de raciocínio como ponto de partida, propomos a dialética como aliada ao tipo de ambiente favorável ao diálogo racional, produtivo e cooperativo descrito pelos autores.

Um dos autores contemporâneos proeminentes nesse campo de estudo é Douglas Walton (1998, 1999, 2007a, 2013). Para Walton (2007a), a melhor maneira de conceber a dialética, em nosso contexto atual, é nos aproximar da concepção grega antiga, que a entende como a arte da conversação racional, a qual utiliza suas ferramentas para analisar e avaliar argumentos e movimentos argumentativos ${ }^{8}$ em determinado contexto de conversação. Mais detalhadamente, ele a define (Ibid., p. 61) como a arte da discussão racional em que um questionador e um respondente raciocinam juntos por um processo de perguntas e respostas composto por cadeias de argumentação. Tal processo, aponta o autor (Ibid.), gera uma espécie de benefício 
terapêutico e ganho em aprendizado em virtude do esclarecimento de ambiguidades e do teste de plausibilidade das afirmações feitas.

O propósito da dialética, tal como concebida por Walton (2007a), não é de persuadir alguém a fazer algo ou aceitar determinada afirmação como verdadeira ou falsa. Sua

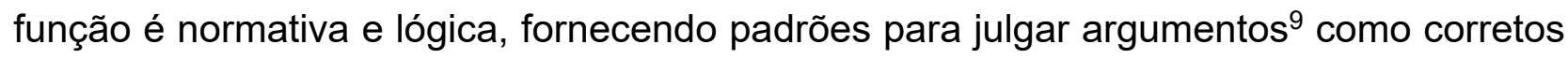
ou incorretos, fortes ou fracos, plausíveis ou implausíveis, racionalmente justificáveis ou não racionalmente justificáveis. Sua natureza é pragmática (WALTON, 2007a), isso é, dependente de um contexto de conversação que pode ter o propósito de refinar um ponto de vista sobre determinado assunto, mas também pode ter o propósito de deliberar quanto a qual curso de ação tomar ou de negociar racionalmente em uma situação em que duas ou mais partes procuram resolver algum conflito de interesses ${ }^{10}$.

\section{Dialogo examinativo}

Walton (2007a) define um diálogo como uma troca verbal entre duas (ou mais) partes $^{11}$ em concordância com algum arquétipo subjacente (implícito ou não), o qual respeita um conjunto de convenções e expectativas. Diálogos formais, por conseguinte, são entendidos como modelos normativos ou estruturas colaborativas de conversação caracterizadas por objetivos bem definidos, regras e métodos (WALTON, 1998). Essas estruturas formais permitem que aqueles que participam do diálogo raciocinem de maneira ordenada a fim de alcançar seus objetivos.

Walton (1998; 2007a) distingue diferentes tipos de diálogos a partir de seus diferentes objetivos e características. Embora cada modelo possua suas idiossincrasias, é possível discriminar quatro blocos construtores de qualquer sistema dialético (WALTON, 2007a, p. 21): (1) dois participantes, o questionador e o respondente ${ }^{12}$; (2) tipos distintos de movimentos (atos de fala) que cada participante tem permissão de realizar em cada turno $^{13}$; (3) uma sequência de movimentos cuja adequação depende do tipo de movimento precedente avançado pela outra parte; e (4) o objetivo geral do diálogo. Idealmente, cada etapa do diálogo deve proceder a fim de atingir o objetivo geral do diálogo. Do mesmo 
modo, cada movimento deve ser avaliado de acordo com o quão produtivo é para atingir tal objetivo.

De acordo com Walton (WALTON, 2007a), Aristóteles desenvolveu um sistema dialético de classificações em que distinguia diferentes tipos de raciocínios e de argumentos. Esse sistema pode ser interpretado, à luz da nova dialética, como a primeira tentativa de discriminar sistematicamente diferentes estruturas de diálogo formalizáveis. Em sua obra Refutações Sofísticas (1991), Aristóteles escreve que há um contexto de conversação cujos argumentos utilizados são baseados nas opiniões sustentadas pelo respondente e necessariamente por aquele que afirma ter conhecimento da matéria em questão, os argumentos examinacionais ${ }^{14}$ (Ibid.,165a38-165b12). Nesse contexto, o questionador procede de modo a testar as visões do respondente, submetendo-as a escrutínio crítico. Como explica Walton (2007a, p.87), os argumentos examinacionais descritos por Aristóteles são aqueles usados para "testar o conhecimento do respondente"15. Dentre os diferentes tipos de diálogos classificados na nova dialética, um modelo acomoda as referidas características descritas por Aristóteles, o diálogo examinativo ${ }^{16}$. Walton (2006, p.763) salienta que Aristóteles já "via o [diálogo] examinativo como um tipo distinto de diálogo de alguma importância, [...] importância suficiente para tentar formular algumas regras para ele"17.

Aqui, defenderei que esse modelo de diálogo pode desempenhar um papel especial no exercício das disposições de um pensador crítico relacionadas ${ }^{18}$. A fim de caracterizar melhor esse tipo de diálogo, recorro à descrição dada por Dunne, Doutre e Bench-Capon (DUNNE; DOUTRE; BENCH-CAPON 2005),

\footnotetext{
Nesses diálogos [examinativos], uma das partes - o Questionador Q - elicita afirmações e opiniões da outra parte - o Respondente R - com o objetivo de descobrir a posição de $\mathrm{R}$ sobre algum tópico, seja para obter informações sobre a compreensão e o conhecimento de R sobre o tópico, seja para expor alguma inconsistência na posição de R (lbid. $)^{19}$.
}

A partir dessa descrição, entendemos que a situação inicial de um diálogo examinativo $(D . E)^{20}$ é aquela em que o questionador se depara com uma visão apresentada pelo respondente acerca de algum tópico em pauta e, então, procura 
compreender melhor tal visão, podendo, em seguida, testá-la criticamente caso tenha dúvidas quanto à sua plausibilidade.

Para Walton (2006), há dois objetivos gerais associados ao D.E. O primeiro objetivo consiste na obtenção de informação, em que o proponente questiona seu interlocutor com a intenção de obter quaisquer informações desejadas, de modo que estas reflitam, com a maior clareza e coerência possível, o posicionamento de tal interlocutor sobre algum tópico ${ }^{21}$. O segundo objetivo consiste no teste da confiabilidade e da plausibilidade das informações obtidas via questionamento e argumentação crítica.

É possível fragmentar teoricamente o D.E em dois estágios ou níveis básicos em concordância com seus objetivos embora, em um caso real, possa ser obscura a linha que distingue esses estágios (WALTON, 2006). Como afirmamos anteriormente, o primeiro estágio possui um caráter exegético. Nesse estágio, o proponente questiona 0 respondente com a finalidade de extrair informações e interpretá-las do modo mais coerente e claro possível. Esse processo ocorre pela obtenção das considerações da visão do respondente, as quais poderão ter sua confiabilidade e plausibilidade testadas no estágio seguinte. Durante esse primeiro estágio, o D.E assume um caráter informativo, dado que o objetivo associado consiste em extrair informações do respondente. Além disso, possui um caráter assimétrico, ou seja, detém a característica de que cada um dos participantes - o questionador e o respondente - possui papéis relativamente distintos ${ }^{22}$ (WALTON, 1998).

O segundo estágio consiste no estágio crítico, em que se usa a argumentação crítica para aferir a plausibilidade do que foi dito, investigando possíveis falhas na argumentação apresentada. Em outras palavras, a argumentação crítica, nesse nível do diálogo, tem a finalidade de investigar os pontos fortes e fracos na estrutura do argumento levantado pelo respondente (WALTON, 2006). Nesse ponto, o D.E assume um caráter crítico argumentativo. O autor (Ibid., 2006), entretanto, salienta que o propósito do aspecto argumentativo do D.E não é calar aquele que é questionado. Táticas como apelo à força, ameaças ou ao medo são inadequadas nesse tipo de diálogo. Nele, o proponente não busca descreditar o respondente ou comprometê-lo com alguma afirmação que possa ser 
usada para, futuramente, desfavorecê-lo. Uma vez definido e esclarecido o posicionamento examinado, a argumentação no D.E deve ter como propósito avaliá-lo criticamente. Vale ressaltar que o que se espera realisticamente desse tipo de diálogo é a compreensão da posição e o teste crítico da argumentação apresentada pelo respondente para que falácias, contradições e outras inconsistências lógicas sejam reveladas. Não é plausível esperar com isso o alcance do que seria a verdade acima de qualquer dúvida quanto a alguma questão controversa (WALTON, 2007a).

Os principais efeitos dessa argumentação, reforça Walton (Ibid.), são dois. O primeiro efeito da argumentação crítica, em um D.E, é que, ao levar em conta os questionamentos e contra-argumentos, o respondente pode modificar sua opinião original ou, ao menos, expressá-la de modo menos vulnerável a objeções. O outro valioso efeito possível é que o respondente apure sua opinião expressa, ao modificá-la, de modo a torná-la mais refinada e qualificada. Além disso, não é apenas o respondente que se beneficia desse tipo de diálogo. Ao compreender melhor o ponto de vista do respondente, tanto o questionador como aqueles que participam do diálogo indiretamente sujeitam-se ao que Walton (2007a) chama de benefício maiêutico ${ }^{23}$.

Ambos os objetivos específicos do D.E almejados durante seus diferentes estágios - a obtenção de claras considerações sobre a visão do respondente acerca de determinado assunto e o teste crítico das mesmas - devem ser alcançados elicitando informações e testando-as em relação ao conjunto de comprometimento do próprio respondente, a outros fatos conhecidos no caso e a demais informações tomadas como verdadeiras pelas partes (WALTON, 2007a). Isso porque tal modelo de diálogo, assim como outras estruturas dialéticas, tem a característica de que uma das partes considera como premissas em sua linha de argumentação os comprometimentos da outra parte. Isso não quer dizer que dados, informações e explicações externas não possam ser utilizados no decorrer do diálogo. A ideia é apenas que o argumento que uma das partes avança só é desenvolvido a partir de premissas que a outra parte possui em seu conjunto de comprometimentos (WALTON, 2007a). 
Como já dito, esse tipo de diálogo se afasta de um caráter central persuasivo, dado que o respondente pode, simplesmente, não ter intenção de convencer o questionador de sua visão (DUNNE; DOUTRE; BENCH-CAPON, 2005), mas - sustentamos - de esclarecê-la, de expor seus méritos epistemológicos e, com esse processo, refiná-la. De modo semelhante, o questionador pode já possuir informações ou crenças sobre o tópico em questão e estar apenas interessado em entender melhor a concepção do respondente ou testar sua plausibilidade e suas virtudes de um ponto de vista racional. Em outras palavras, é possível que o intuito de alguém que examina o ponto de vista de outra pessoa seja, sincera e legitimamente, motivado pelo desejo de compreender suas virtudes lógicas, ou, até mesmo, somente de entender com maior clareza do que trata tal ponto de vista, algo que concorda com as disposições de um pensador crítico que congregamos anteriormente no texto. Walton (2006, p. 764) reforça que "você pode examinar as opiniões de alguém, por exemplo, apenas para ver o que elas são, sem ter outros objetivos de tentar refutá-las ou questioná-las argumentativamente"24.

Aqui, cabe questionar qual é o objetivo último desse modelo de diálogo. Isso porque há um problema geral que se aplica a todos os modelos de diálogo e que diz respeito à sua completude. Em resumo, o problema é quando uma das partes deve cessar o questionamento crítico em resposta a determinada argumentação e, então, aceitar a conclusão da outra parte ou oferecer razões para não o fazer ${ }^{25}$ (WALTON, 2007a). Uma maneira de solucionar esse problema, sustenta o autor (Ibid.), é utilizar a noção de aprofundamento de argumentação para definir um limite do questionamento crítico uma vez que a argumentação atingiu determinado grau de aprofundamento. No caso do diálogo investigado nessa pesquisa, o problema da completude pode assumir uma solução relativamente simples. Uma vez que determinamos que o objetivo último do D.E, tal como interpretado e proposto nesse trabalho, consiste em esclarecer/refinar a visão do respondente sobre algum assunto, basta ao processo que essa visão tenha sido reformulada, seja porque foi articulada e expressa de uma maneira mais clara e de modo menos vulnerável a objeções, seja porque foi defendida via argumentação crítica e, como consequência, refinada ou apurada. Concebido dessa maneira, um D.E pode ser 
concluído sem que sequer tenha chegado em seu estágio argumentativo. Tal seria o caso em que o respondente reformulasse a maneira como expressa sua visão e, com isso, sanasse as dúvidas do questionador quanto a sua plausibilidade. De modo semelhante, uma vez que tenha chegado no estágio argumentativo, um D.E pode ser concluído quando, confrontado pelos questionamentos críticos, o respondente refina, suspende temporariamente ou abandona sua visão sobre o assunto discutido.

\section{O uso do diálogo examinativo no exercício de disposições críticas}

Quais são as possíveis aplicações dessa estrutura dialética à luz do pensamento crítico como ideal pedagógico? A partir das obras que nos chegaram de Aristóteles sobre retórica, é possível argumentar que esse tipo de diálogo possuía relevante papel no contexto dialético grego antigo ${ }^{26}$ (WALTON, 2007a). Na contemporaneidade, Walton (2006) enfatiza o papel do D.E no campo da inteligência artificial, do direito e, de um modo geral, em diálogos em que um indivíduo consulta um especialista ${ }^{27}$ em busca de conselhos e orientações.

Sobre o campo de ação desse modelo de diálogo,

É uma habilidade universal de questionar e raciocinar que pode ser aplicada em muitos, ou mesmo em todos, os domínios do conhecimento e de compreensão. Por uma questão prática, todos podem precisar usar o diálogo examinativo em algum momento ou outro. (WALTON, 2005, p. 154) ${ }^{28}$.

Em suma, entendemos o diálogo examinativo como um modelo que tem o potencial de ser aplicável, virtualmente, a qualquer área de investigação e assunto com os quais podemos nos deparar em contextos escolares e acadêmicos. Acreditamos, ainda, que não só a argumentação de natureza filosófica pode fazer uso adequado de um modelo examinativo de diálogo, mas também discussões de natureza científica. Tal visão me parece razoável, dada a característica que essa estrutura dialética possui de refinar um ponto de vista. Como Walton (2007a) salienta, 
Uma hipótese apresentada no estágio de descoberta de uma investigação científica não será tão próxima da verdade quanto a que foi teoricamente refinada em um grau mais alto e que passou em mais testes com mais dados (WALTON, 2007a, p.119) ${ }^{29}$.

Ainda nos falta explicar como exatamente o D.E, entendido como uma ferramenta dialética, se relaciona às disposições de um pensador crítico salientadas neste trabalho. Em primeiro lugar, recapitulemos que o pensador crítico ideal possui a mente aberta, flexibilidade, atenção e considera com seriedade diferentes opiniões e visões de mundo, bem como as razões subjacentes às mesmas. Em uma situação em que o indivíduo $Q$ percebe que o indivíduo $R$ possui uma visão de mundo diferente da sua, $Q$ poderia, por exemplo, dar início a um diálogo de caráter persuasivo. Isso faria com que $Q$ tivesse, como objetivo, a persuasão de $\mathrm{R}$ de seu ponto de vista e não necessariamente tentar entender melhor o que R sustenta e quais são suas virtudes e méritos do ponto de vista racional. Se esse fosse o caso, em uma situação realística, o diálogo iniciado não favoreceria a disposição de $Q$ de ser flexível e de considerar com seriedade diferentes visões de mundo. Tampouco, favoreceria o exame das razões subjacentes a essas visões. Contudo, dado que entendemos as disposições de um pensador crítico como hábitos mentais ${ }^{30}$, é plausível que o uso do D.E como estrutura dialética de conversação, em casos em que um indivíduo se depara com algum ponto de vista distinto daquele(s) que já considerou, seja bastante adequado. A razão para isso é que, mesmo que o D.E possa surgir em um contexto de conflito de opiniões, não necessariamente $Q$ possui uma opinião formada sobre o assunto. Além disso, ainda que possua alguma visão sobre o assunto, $Q$ não necessariamente busca persuadir $R$ de sua posição. Em outras palavras, o foco de $Q$ não está em suas próprias concepções, mas na compreensão do ponto de vista de $\mathrm{R}$ e em seu exame criterioso sem necessariamente ter o objetivo de refutá-lo, embora essa seja uma possibilidade, mesmo que esse ponto de vista contrarie suas próprias crenças e opiniões ${ }^{31}$.

O segundo grupo de disposições relacionado consiste na sensibilidade aos próprios vieses, preconceitos e tendências e na honestidade ao enfrentá-los. A sensibilidade e honestidade em enfrentar seus próprios preconceitos é algo desenvolvido, especialmente, 
no respondente durante o D.E. Como afirmamos, os argumentos avançados nesse tipo de diálogo são baseados e dirigidos às opiniões sustentadas pelo respondente. Uma vez que um indivíduo que sustenta determinada visão permite ser examinado criticamente, exame que pode trazer à luz suas fraquezas, falhas e inconsistências lógicas, o mesmo se sujeita ao reconhecimento público de que essa visão pode não ser tão bem sustentada do ponto de vista racional como pensava antes. Entendemos que esse processo, se recorrente, pode, gradativamente, tornar o respondente ciente de seus preconceitos e vieses e capacitá-lo a encarar suas próprias tendências de um modo mais crítico, honesto e consciente.

Associada às disposições anteriores, a terceira atitude relacionada consiste em reconsiderar e revisar os próprios pontos de vista quando uma reflexão honesta sugere que a mudança é justificada. Recapitulo que um dos efeitos do D.E é a modificação da opinião original do respondente ou, ao menos, a reformulação do modo como este expressa tal visão. Essa reformulação torna sua visão mais clara e menos vulnerável a objeções. Acredito que esse efeito só pode ser obtido se o respondente, de fato, reconsidera e revisa suas próprias concepções, especialmente quando o processo é feito de maneira menos parcial que o habitual, envolvendo mais de uma pessoa. Uma vez iniciado, o D.E coloca o respondente em uma posição que requer a elucidação e, possivelmente, o reajuste de sua visão sobre algum assunto. Portanto, o respondente necessariamente revisa suas concepções, seja para explicá-las e comunicá-las de maneira mais eficiente, seja para sustentá-las diante dos questionamentos levantados pelo questionador. Em um diálogo em que seu objetivo consiste, essencialmente, em responder a questionamentos ao elucidar e defender sua própria visão, é praticamente inevitável que o respondente exercite tal hábito.

Por fim, aponto que aquele que pensa criticamente deve adequar suas crenças às evidências disponíveis. Ainda que sejam considerados os comprometimentos, e não necessariamente os estados psicológicos de crença dos indivíduos durante a análise de um diálogo formal, acredito que aqueles que são engajados direta ou indiretamente em um D.E são expostos a ideias e razões legítimas do ponto de vista racional. Por 
conseguinte, mesmo que essa exposição ocorra em um contexto de sala de aula artificial e controlado, por assim dizer, em que se busca exercitar as disposições mencionadas deliberadamente, o fato de tratar de assuntos dos mais variados temas presentes na vida dos indivíduos participantes implica que o uso do D.E efetivamente fomenta a reflexão e o refinamento crítico das crenças de todos os envolvidos.

\section{Considerações finais}

Nessa pesquisa, apresentei uma das concepções encontradas na literatura disponível sobre o pensamento crítico e como este compõe, ou deveria compor, uma das metas de sistemas de ensino de escolas e universidades. Vimos que aquele que pensa criticamente sobre determinado assunto detém habilidades e disposições características. Em seguida, apontei o contraste de algumas disposições de um pensador crítico com tendências a vieses, preconceitos e outras falhas de ordem cognitiva em que os seres humanos tipicamente incorrem. Dentre os possíveis caminhos para mitigar essas tendências, foi tomada como ponto de partida a criação de ambientes educativos que favoreçam o diálogo racional, colaborativo e flexível. Para desenvolver a premissa escolhida, recorri ao arcabouço teórico fundamentado na nova dialética de Douglas Walton e argumentei em favor de um tipo específico de diálogo, o diálogo examinativo (D.E), como ferramenta pedagógica disponível para o exercício das disposições críticas por nós relacionadas.

Diversas questões ainda permanecem em aberto. Penso que um dos pontos que devem ser considerados é que há diversos subtipos de diálogos examinativos. Podem ser interpretados como subtipos de diálogos examinativos, por exemplo, a acareação (WALTON, 2018), o interrogatório (WALTON, 2007b), a consulta de um especialista (WALTON, 1998), testes (WALTON, 2007b) e, possivelmente, outros subtipos de diálogo como entrevistas (WALTON, 1998). O objetivo desses e de outros subtipos pode variar, assim como os objetivos e motivações dos participantes em cada um deles. O objetivo do proponente em uma acareação, por exemplo, consiste em extrair uma contradição ou 
alguma informação que favoreça a sua parte na disputa (WALTON, 2007b), o que contrasta com o objetivo de refinar a visão do respondente sobre alguma questão como foi proposto aqui.

Isso posto, pode ser questionado se o diálogo investigado nesse trabalho trata-se de um amalgamado de diferentes subtipos de diálogo examinativo já existentes ou até mesmo de um subtipo novo. Em todo caso, é preciso entender o que difere normativamente o subtipo de diálogo que investigamos dos demais subtipos. Seria sua natureza diagnóstica, o que faria dele um "diálogo diagnóstico"? Seria seu objetivo de apurar e refinar a visão do respondente, o que tornaria mais adequado nomeá-lo "diálogo apuratório"? Seriam suas motivações ou mesmo seu papel pedagógico? Se esse último for o caso, seu uso se restringiria a contexto pedagógicos ou poderia ser empregado no cotidiano dos estudantes fora de sala de aula?

Além disso, o fato de existirem diferentes subtipos de diálogo examinativo e que cada um deles pode variar em seus objetivos gerais e específicos implica também a dificuldade de formular regras precisas para conduzir o D.E do modo como foi investigado nessa pesquisa. Por exemplo, me parece claro que no tipo de diálogo que descrevemos não é conveniente que haja um tempo estipulado para que cada uma das partes realize seu movimento. Em contraste, em um teste oral, em que um professor examina o aluno quanto a algum conteúdo específico, é argumentável que deve haver tempo prédeterminado para que o respondente exerça seu direito de réplica.

Todas as questões até aqui levantadas demandam investigação e debate. Nesse sentido, penso que o objetivo dessa pesquisa foi alcançado e acredito em seu papel no fomento de uma discussão mais presente sobre o uso de estruturas dialéticas para a promoção e desenvolvimento do pensamento crítico em indivíduos dentro e fora de sala de aula.

\section{Referências}

ARISTÓTELES. Sophistical refutations. In: The complete works of Aristotle Vol.I. Tradução de: Jonathan Barnes. Princeton: Princeton University Press, [1991]. 
DINUCCI, Aldo. O elenchus como principal instrumento da pedagogia socrática.

Saberes, Natal, RN, v.1, n.1, dez. 2008.

DUNNE, Paul; DOUTRE, Syvlie; BENCH-CAPON, Trevor. Discovering Inconsistency through Examination Dialogues. Proceedings IJCAI-05 (International Joint Conferences on Artificial Intelligence), Edinburgh, p.1560-1561, jan. 2005.

ENNIS, Robert. Critical thinking: a streamlined conception. Teaching Philosophy, v.14, n.1, p. 5-24, Mar. 1991.

FACIONE, Peter. Critical thinking: a statement of expert consensus for purposes of educational assessment and instruction. Research findings and recommendations (Report). Newark: American Philosophical Association,1990. Disponível em: https://eric.ed.gov/?id=ED315423. Acesso em 19 dez. 2020.

GUZZO, Guilherme; GUZZO, Valdemir. O pensamento crítico como ferramenta de defesa intelectual. Conjectura: Filos. Educ., Caxias do Sul, v.20, n.1, p.64-76, jan./abr. 2015.

GUZZO, Guilherme; LIMA, Valderez. O desenvolvimento do pensamento crítico na educação: uma meta possível? Educação Unisinos, São Leopoldo. v.22, n.4, p.334343, out/dez. 2018.

HAIDT, Jonathan. The emotional dog and its rational tail: a social intuitionist approach to moral judgment. Psychological Review, Charlottesville, v. 108, n.4, p.814-834, Feb./Nov. 2001.

HITCHCOCK, David. Critical thinking as an education ideal. In: On reasoning and argument: essays in informal logic and on critical thinking. [S.I] Springer, 2017. cap.30, p.477-497.

HOAGLUND, John. Critical thinking: a socratic model. Argumentation, Norwell, MA, v.7, p.291-311, 1993.

LORD, Charles; ROSS, Lee; LEPPER, Mark. Biased assimilation and attitude polarization: the effects of prior theories on subsequently considered evidence. Journal of Personality and Social Psychology, Palo Alto, v. 37, n.11, p.2098-2109, Feb. 1979.

MCCAIN, Kevin. The nature of scientific knowledge: an explanatory approach. Cham, Switzerland: Springer International Publishing, 2016.

WALTON, Douglas. The new dialectic: conversational context of argument. Toronto: University of Toronto Press, 1998. 
WALTON, Douglas. The new dialectic: a method of evaluating an argument used for some purpose in a given case. ProtoSociology: an international journal of interdisciplinary research, v.13, p.70-91, 1999.

WALTON, Douglas. Argumentation methods for artificial intelligence in law. Heidelberg: Springer, 2005.

WALTON, Douglas. Examination dialogue: an argumentation framework for critically questioning an expert opinion. Journal of Pragmatics, Windsor, v.38, n.5, p.745-777, 2006.

WALTON, Douglas. Dialog theory for critical argumentation. Filadélfia: John Benjamins Publishing Company, 2007a.

WALTON, Douglas. Witness testimony evidence: argumentation, artificial intelligence and law. Cambridge: Cambridge University Press, 2007b.

WALTON, Douglas. Argumentation schemes. Nova lorque: Cambridge University Press, 2008.

WALTON, Douglas. Methods of argumentation. Nova lorque: Cambridge University Press, 2013.

WALTON, Douglas. Conflict diagrams for cross-examination dialogues. Argumentation \& Advocacy, v.4, n.3, p.199-218, Mar., 2018.

\section{Notas}

1 Tradução minha.

${ }^{2}$ Ver Hitchcock (2017, p.479).

3 Tradução minha.

4 Tradução minha.

${ }^{5}$ Aqui, lanço mão do arquétipo proposto por Hitchcock (2017, p. 477) de "pensador crítico ideal", isso é, aquele que pensa criticamente quando é apropriado e o faz bem. A intenção, com isso, não é estabelecê-lo como uma condição a ser concretamente alcançada, mas como um referencial em direção ao qual podemos sistematizar nossas metas educacionais sem que deixemos de ancorá-las em expectativas realistas de sucesso.

6 Nesta pesquisa, entenderei "disposições comportamentais", "atitudes" e "hábitos mentais" intercambiavelmente, tal como Facione (1990).

7 Tradução minha. 
${ }^{8}$ Podem ser considerados movimentos argumentativos, por exemplo, asserções, questões, definições e retratações. ${ }^{9}$ Nesse contexto, um argumento é entendido como um construto social fruto da interação entre diferentes
partes e não apenas um conjunto isolado de premissas e conclusões.

${ }^{10}$ Algumas das diferentes estruturas de diálogos que atendem a diferentes propósitos e objetivos são encontradas em Walton (1998; 2007a).

11 Uma "parte", nesse contexto, é entendida como um conjunto finito de participantes que sustenta alguma atitude (pro, contra ou neutro) em relação a algum ponto de vista. Um diálogo pode ter duas, três ou $n$ partes contanto que o papel de cada uma delas durante a conversação seja exercido por algum indivíduo. Também é interessante notar que o mesmo indivíduo pode assumir o papel de mais de uma parte a fim de examinar diversos lados de uma questão (WALTON, 2007a, p.51).

${ }^{12} \mathrm{Em}$ síntese, o questionador, às vezes referido como proponente, é aquele realiza perguntas enquanto cabe ao respondente as réplicas. Tipicamente o questionador sustenta um ponto de vista o qual o respondente acredita ser duvidoso e, por seguinte, carrega o que Walton chama de "ônus de prova". Contudo, dependendo do tipo de diálogo, o respondente pode carregar o ônus de prova ao avançar em defesa de uma tese a qual será criticamente avaliada pelo questionador. É interessante ressaltar que o ônus de prova pode recair sobre ambos o questionador e o respondente no mesmo diálogo dependendo dos movimentos argumentativos permitidos a cada parte.

${ }^{13}$ Um turno, no original round, é um par de movimentos revezados entre o proponente e o respondente.

14 Tradução minha.

15 Tradução minha.

${ }^{16}$ No original, Examination Dialogue (PAUL; TREVOR, 2005; WALTON, 2006). Tradução minha.

17 Tradução minha.

${ }^{18}$ Ver a seção Habilidades e disposições de um pensador crítico e sua viabilidade como meta educacional.

19 Tradução minha.

${ }^{20}$ Deste ponto em diante, me referirei ao diálogo examinativo investigado nesse trabalho pela sigla "D.E".

${ }^{21}$ Algo que confere um caráter exegético ao processo. Walton (2006, p. 772) admite até mesmo a possibilidade da exegese de um texto escrito sob a noção de diálogo examinativo.

22 Em contraste, um exemplo de diálogo simétrico seria o diálogo persuasivo, em que ambas as partes possuem papéis relativamente equivalentes, isso é, de persuadir a(s) outra(s) parte(s). No caso do primeiro estágio do D.E, o diálogo é de caráter assimétrico porque o questionador possui o objetivo de extrair informações claras e precisas das visões do respondente enquanto esse último possui o objetivo de disponibilizar/ceder tais informações.

${ }^{23}$ Clara referência ao processo de investigação característico de Sócrates nos diálogos de Platão, frequentemente chamado de Elenchus (DINUCCI, 2008). 
24 "questionar argumentativamente" deve ser entendido aqui no mesmo sentido de refutar. Tradução minha.

${ }^{25}$ Frisamos que não necessariamente o questionador deve aceitar a conclusão proposta pelo argumento do respondente ao final do processo de questionamentos críticos. Contudo, uma vez que os argumentos do respondente são considerados plausíveis pelos participantes, o fato do questionador não se comprometer com sua conclusão sem oferecer razões para isso faz de sua postura, nesse contexto específico, ilógica, não razoável ou, ao menos, conflitante com os requerimentos normativos necessários para engajar em uma argumentação racional (WALTON, 2008, p.36).

${ }^{26}$ Como aponta o autor (WALTON, 2005, p.154), Aristóteles entendia o diálogo examinativo, ou alguma protoversão dele, como aplicável a praticamente qualquer tipo de assunto, tendo as premissas de seus argumentos baseadas na opinião do respondente e cujo objetivo desses argumentos consiste em testar o conhecimento que o respondente supostamente detém.

${ }^{27}$ No original, Expert Consultation Dialogue (tradução nossa). Sobre esse tipo de diálogo, ver Walton (1998, 2006).

${ }^{28}$ Tradução minha.

29 Tradução minha.

${ }^{30}$ Ver nota 6.

${ }^{31} \mathrm{O}$ efeito nesse cenário pode ser a persuasão racional de qualquer um dos participantes. Contudo, esse efeito é apenas colateral, isso é, não compõe as motivações nem mesmo os objetivos do D.E.

\section{(c) (1) (8) (1)}

This work is licensed under a Creative Commons Attribution-NonCommercial 4.0 International (CC BY-NC 4.0) 